\section{P0-0965 AN AUDIT IN PAEDIATRIC PRESCRIBING}

${ }^{1} \mathrm{~A}$ Puttick, ${ }^{1} \mathrm{C}$ Anderson, ${ }^{1} \mathrm{M}$ Luney, ${ }^{1} \mathrm{O}$ Lucas, ${ }^{1} \mathrm{~A}$ Robinson, ${ }^{1} \mathrm{~A}$ Prabhu, ${ }^{2} \mathrm{R}$ Jackson, ${ }^{3} \mathrm{~W}$ Kelsall. 'School of Clinical Medicine, University of Cambridge, Cambridge, UK; ${ }^{2}$ Medical School, University of Newcastle Upon Tyne, Newcastle, UK; ${ }^{3}$ Paediatrics, Cambridge University Hospitals NHS Foundation Trust, Newcastle, UK

\subsection{6/archdischild-2014-307384.1584}

Background and aims Prescribing errors are common in hospitals. Within Addenbrooke's, the paediatrics department was found to make more prescribing errors than any other. We aimed to undertake a closed-loop audit of prescribing errors in paediatrics at Addenbrooke's.

Methods Data was collected from all readily available drug charts on all paediatric wards, once weekly over 6 weeks (first cycle May 2013, second cycle Oct-Nov 2013). Each drug chart was inspected for 'pharmacist identified' errors, with minimum standards set in key areas.

Between cycles, interventions included: meeting of senior clinicians and pharmacist; prescriber received standardised email after errors, for discussion with consultant; follow-up of non-responders; audit data and protocol disseminated; paediatric teaching on prescribing.

Results A total of 3436 (first cycle) and 3516 (second cycle) prescriptions were reviewed with $12 \%$ and $16 \%$, respectively, containing an error. The commonest error in both cycles was drug name.

Set standards were achieved for correct drug name and dose, but not for legible signature, allergy documentation or weight documentation.

The proportion of drug charts with 0 errors increased in the second cycle. Those with 1-5 errors decreased. However, the proportion of charts with $6+$ errors increased (many 'high error' charts contained multiple errors by one prescriber).

Conclusions The implemented changes had no significant effect on the rate or type of errors identified. Minimum standards are not being met in some areas. It is possible that a few 'rogue' prescribers may be responsible for many errors, in which case targeted strategies may be effective.

\section{P0-0966 CLINICAL ASSESSMENT OF HYPOTONIA: USING DESIGN RESEARCH TOWARDS CONSENSUS}

P Naidoo, RWE Joubert. Occupational Therapy Health Sciences, University of KwaZuluNatal, Durban, South Africa

\subsection{6/archdischild-2014-307384.1585}

Background and aims The clinical assessment of hypotonia remains contentious in the literature. The reality is that the assessment is often subjective in nature. Despite the underlying

\section{Abstract P0-0966 Table 1 Phases of the study}

\begin{tabular}{|c|c|c|}
\hline \multirow{3}{*}{$\begin{array}{l}\text { PRELIMINARY } \\
\text { PHASE }\end{array}$} & $\begin{array}{l}\text { Identify current evidence and } \\
\text { identify gaps in the literature }\end{array}$ & Systematic Review \\
\hline & \multirow{2}{*}{$\begin{array}{l}\text { Identify and analyse the problem - } \\
\text { researchers and practitioners in } \\
\text { collaboration }\end{array}$} & $\begin{array}{l}\text { Survey: Current Practices of occupational } \\
\text { therapists, physiotherapists and paediatricians }\end{array}$ \\
\hline & & $\begin{array}{c}\text { Reduction of items and } \\
\text { Consensus via a Delphi Process }\end{array}$ \\
\hline $\begin{array}{l}\text { PROTOTYPING } \\
\text { PHASE }\end{array}$ & $\begin{array}{l}\text { Development of prototype solutions } \\
\text { guided by theory, existing principles } \\
\text { and technology }\end{array}$ & $\begin{array}{l}\text { Inductive, abductive and deductive logic used } \\
\text { to analyse data from previous phase - } \\
\text { combined with a framework (ICF) and technica } \\
\text { guidelines (ISO) towards the development of a } \\
\text { clinical algorithm }\end{array}$ \\
\hline \multirow[b]{2}{*}{$\begin{array}{l}\text { ASSESSMENT } \\
\text { PHASE }\end{array}$} & Methodological Rigor & AGREE II Tool for evaluation of process \\
\hline & $\begin{array}{c}\text { Epistemic Correlation and Content } \\
\text { Analysis }\end{array}$ & Expert Feedback and Critique' \\
\hline
\end{tabular}

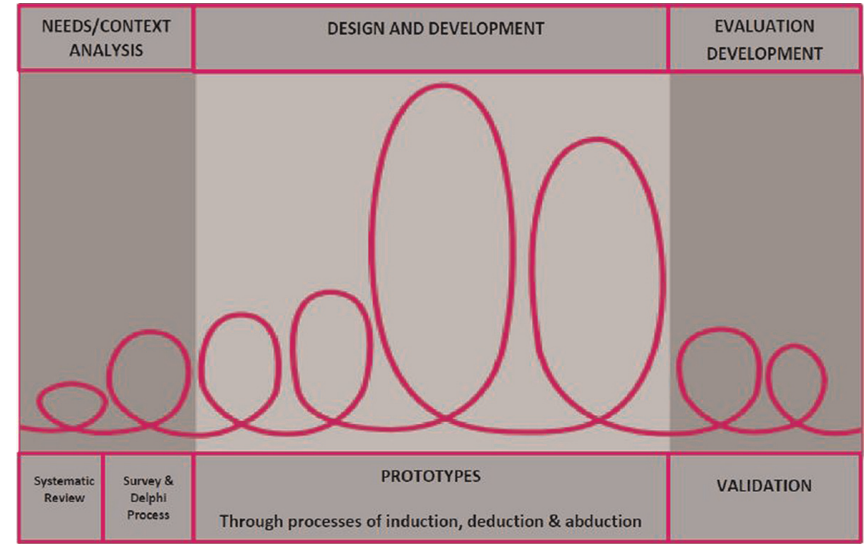

Abstract P0-0966 Figure 1 Cyclic process adopted in this study (adapted from Mckenney, 2001)

causative factors, the clinical presentation of hypotonia is however considered to be similar in most cases. Differentiating the likely causes of hypotonia is important in sparing some infants and children from invasive diagnostic tests and there also exist a number of causes of hypotonia for which there is no definitive laboratory or imaging tests, namely idiopathic hypotonia, so the role of the clinical and developmental assessments remain important. The author describes a process in moving clinicians towards consensus.

Methods

Design Research, using across stage mixed methods was used, within a pragmatic stance. Design research acknowledges the complex and dynamic relationship between theory and application and provides a relevant foundation to guide practice by methods that are both theoretically underpinned and empirically tested. The author combined evidenced-based methods that assisted in the design of a clinical algorithm for practice (Table 1). Three phases were implemented viz. preliminary phase, prototyping and assessment phase.

The visualisation of the research process is described in Figure 1 below.

Results and conclusions With use of design research, and following a systematic process, the authors were able to formulate a process in order to initiate movement towards consensus on the assessment of hypotonia. These processes followed a systematic and evidenced-based process and culminated in the development of a clinical algorithm.

\section{PO-0967 THE USES OF CLINICAL CASE AS A TOOL OF TEACHING LEARNING IN THE DISCIPLINE OF PAEDIATRICS AT THE FACULTY OF MEDICINE PETRÓPOLIS - RJ - BRAZIL}

1E Veiga, ${ }^{1}$ A Veiga, ${ }^{3}$ A Simeoni. 'Pediatria, Faculdade Medicina de Petrópolis, Petrópolis, Brazil; ${ }^{2}$ Pediatria, Faculdade Medicina de Petrópolis, Petrópolis, Brazil; ${ }^{3}$ Graduação Em Medicina, Faculdade Medicina de Petrópolis, Petrópolis, Brazil

\subsection{6/archdischild-2014-307384.1586}

The Curriculum Brazilian Guidelines state that: "The structure of the degree course in medicine should use methodologies that emphasise active student participation in knowledge construction and integration between the content..." On the study site, the undergraduate medicine has six years duration, with workload 8032 hs. Of this total, 3472 hs correspond to the clinical period when the teaching / learning process occurs to practical 